Editorial

\title{
COVID-19 PANDEMIC AND DENTISTS
}

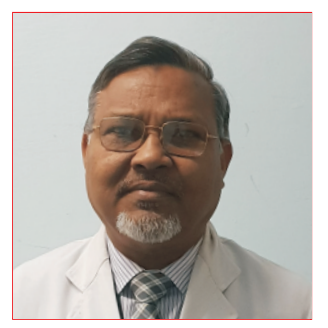

\section{COVID-19 PANDEMIC AND DENTISTS}

The pandemic Covid-19 has opened new challenges before the professionals and health care workers worldwide. The disease which originated from Wuhan in late 2019 , has now spread worldwide. The most remarkable thing about the disease is its variable behavior. While some positive cases are cured on one side, but some succumb even after receiving best possible medical treatment. Considering the highly contagious nature of the disease, the lockdown, quarantine and social distancing has been taken as important measures to control its spread. This is in addition to self quarantine at extraordinary scale.

Although it would be more appropriate to follow WHO interim guidance for infection prevention and control during Covid-19 pandemic. But this is a controversial issue that whether dentists should provide routine dental care to asymptomatic patients or not. In the existing circumstances, it is wise to postpone the required routine dental care to symptomatic patients and elective dental procedures and emergency dental procedures should be done but a strategy should be chalked out before doing such cases.

This has been unanimously accepted that social distancing is an important measure to prevent spread of infection. However, while performing emergency procedures on operation table, it becomes almost impossible to maintain principles of social distancing but moral responsibility is always there to minimize the fear of spread of infection to patients, attendants and health care workers. This is interesting to note that different guidelines are being released different bodies for attending patients suffering from dental ailment. Dental Council of India, Indian Dental Association and other organizations have issued guide line on this aspect. Hence, MOHFW issued a unified and dynamic guidelines on $19^{\text {th }}$ May 2020 , which is subject to updating time to time, as required. ${ }^{1}$ In developed nations too, dental treatment services are treated differently.

Since till now no authentic treatment of Covid-19 is available. No vaccine has been developed. Many treatment protocols are under research and investigation. PPE should be considered as an important tool to control the disease - to limit and to prevent the spread of the disease and it should be used when providing urgent treatment to any patient. Further, delaying the elective procedure would reduce the burden of routine patients also.

\section{PPE (Personal protective equipment) and GOVT. RECOMMENDATIONS}

The WHO has recommended that individuals with respiratory symptoms should wear a medical mask and consult a medical health practitioner if experiencing fever, cough and dyspnoea. Studies have revealed that wearing a mask by a source is more advantageous and protective rather than when used by receiver. However, a health care worker should wear a medical mask when entering a ward or work place where Covid-19 suspects / or confirmed cases are admitted. But, respirators are preferred over face mask. Same should be used when performing aerosol generating surgical procedures e.g., tracheal intubation, tracheostomy, CPR etc. However, all those dental procedures which produce aerosols and splatters are good health risk to dental health service providers and in such situations they must wear it. The aerosol particle size ranges from $3-10$ $\mathrm{nm} \quad(0.03-0.1 \mu \mathrm{m})$ and Covid -19 measures around $120 \mathrm{~nm}(0.12 \mu \mathrm{m})$. For filtration of this range of particle size, a FFP 3 respirator is most appropriate which allows a filtration rate of about $99 \%$ of all particles measuring up to $0.6 \mu \mathrm{m} .^{2}$

\section{SPECIFIC PREACUTIONS FOR DENTISTS}

In a dental clinic or hospital , this is necessary to protect staff, nurses, paramedics, residents and supporting staff from cross infection in routine as well as in current scenario. The best practices of cross infection control is hand disinfectant, PPE, disinfection of surfaces and sterilization of instruments and equipments. Sodium hypochlorite $0.1 \%$ has been found effective against corona virus. ${ }^{3}$ Optimal use of telephonic consultancy has been approved as guideline from $\mathrm{MCl}$ and $\mathrm{DCl}$. The institutes 
must adapt these guidelines and notify the phone number of consultants for control by contact spread of infection and prevent cross infection. While taking the history of a patient, stress should be given to obtain a history of travel, and symptom pertaining to Covid -19 also.

\section{LABORATORY INVESTIGATIONS:}

Suspect cases should be screened for the virus with nucleic acid amplification tests (NAAT), such as RT-PCR. ${ }^{4,5}$ This is a nuclear-derived method for detecting the presence of specific genetic material from any pathogen, including a virus. In RT- PCR, the sample may be obtained from swab from throat or nose. This investigation takes about 24-48 hours . The Covid positive patients should taken up accordingly. This should be also kept in mind that negative result doesn't preclude Covid 19 infection and it should be combined with signs and symptoms of respiratory infection, patients' history and epidemiological information. A suspected patient should also be tested for other espiratory pathogens using routine laboratory procedures, considering as co-infection can occur. Further, all suspected patients should be tested for COVID19 virus even though another respiratory pathogen is found.

\section{GUIDELINES FOR DENTAL PROCEDURES:}

Recently Dental Council of India has published guidelines for general and comprehensive clinical care for patients attending dental colleges for their treatment. ${ }^{6}$ According to this every dental should have a pre-screening triage area and comprehensive dental clinic to attend all patients. An appeal to non emergency patients should be made to postpone their dental treatment to prevent cross infection. In emergency situation the patient should wear a mask. The patients should pe screened for Covid-19 and current dental complaint. Body temperature of all the employees should be recorded at the time of entry in the dental college and individual lwith illness should not be allowed to work.

1. Elective procedures to be avoided. For all emergency procedures, if the investigation report is not available, the patient should be considered as a positive patient and care should betaken in same spirit.

2. Emergency surgical procedures should be done only in those cases where delay in treatment may be fatal or may cause permanent disability. ${ }^{7}$

3. Clinicians should use N 95 (PPE 2) mask and face shield in every case as a minimum requirement. ${ }^{8}$ This equipment prevents spread by droplet. This kit helps protect during aerosol generating procedures like use of handpieces, ultrasonic instruments ec). In addition, triple layed protection gowns with head should be used to prevent aerosol based transmission.

4. Povidine iodine has been found to possess viruidal activity and has been recommended to use as reliable agent part preparation prior to surgery. It may be used as oral rinse brfore the oral surgical patients. ${ }^{9}$ The use of povidone iodine nasal spray and mouthwash during the current COVID-19 pandemic may protect healthcar workers and reduce cross infection. ${ }^{10}$

5. Extraoral radiographs, like OPG or cone beam CT should be preferred over intraoral radiographs, as occasionally they produce gagging and coughing,

6. For fractures of jaw, closed procedures should be preferred over open procedures, further extraoral route should be preferred over intraoral route.

7. A suspected or confirmed Covid -19 infection patients should be treated only in negative pressure theatre or airborne infection isolation room AlIRs

\section{CONCLUSION :}

COVID-19 pandemic has opened new challenges before the clinicians and health care workers. Certain precautions, if taken, may help prevent the spread of infection, protection of professionals as well as treatment of COVID19 infectedpatients. 


\section{REFERENCES}

1. https://www.mohfw.gov.in/pdf/DentalAdvisoryF.pdf

2. Health and Safety Executive. Evaluating the protection afforded by surgical masks against influenza bioaerosols: Gross protection of surgical masks compared to filtering facepiece respirators. 2008. Available at https://www.hse.gov.uk/research/rrpdf/rr619.pdf(accessed March 2020).

3. Kampf G, Dodt T, Pfaeder S, Steinmann E (2020) Persistence of corona viruses on animate surfaces and their inactivation with biocide agents. J Hosp Infect 104:246

4. https://www.iaea.org/newscenter/news/how-is-the-covid-19-virus-detected-using-real-time-rt-pcr

5. https://apps.who.int/iris/bitstream/handle/10665/331329/WHO-COVID-19-laboratory-2020.4eng.pdf?sequence=1\&isAllowed=y

6. http://www.dciindia.gov.in/Admin/NewsArchives/DCI\%20Guidelines\%20on\%20COVID-19.pdf

7. Rishi Kumar Bali, Kirti Chaudhry,- Maxillofaciaal Surgery and COVID19. . J. Maxillofac. Oral Surg. .https://doi.org/10.1007/s12663-020-01361-8

8. (https://aocmf3.aofoundation.org/\#o=News\%20Date\%20Facet,Descending. Accessed 30 Mar 2020.)

9. Kirk-Bayley J, Challacombe S, Sunkaraneni V, Combes J (2020)

10. https://doi.org/10.2139/ssrn.3563092

Prof. S. S. Ahmed

Chairman

Deparment of Oral and Maxillofacial Surgery

Dr. Z. A. Dental College

Aligarh Muslim University, Aligarh

Email : drssahmed@msn.com 